\section{Antibody Capture Assay}

T. Arndt

Bioscientia Institut für Medizinische Diagnostik GmbH, Ingelheim, Deutschland

Synonym(e) Antikörper-capture-Assay; m-capture assay; $\mu$-capture assay

Englischer Begriff antibody capture assay

Definition Variante des heterogenen - Immunoassays zum Nachweis von Antikörpern.

Beschreibung Die Durchführung erfolgt als SandwichAssay. An eine Festphase (z. B. Röhrchenwand oder $>$ Mikrotiterplattenkavität) ist entweder das zu dem bestimmenden - Antikörper korrespondierende Antigen oder ein Fängerantikörper fixiert. Letzterer hat die Aufgabe, entweder alle Immunglobuline des Patientenserums oder alle Immunglobuline einer Klasse zu binden. Bei der Bindung von IgM spricht man von einem $\mathrm{m}$ - oder $\mu$-capture assay.

- Bei Verwendung Antigen-beschichteter Reaktionsgefäße wird der zu bestimmende (für das Antigen spezifische) Antikörper aus dem Patientenserum gebunden. Nach einem Waschschritt wird mit enzymmarkierten Anti-Human-Immunglobulin-
Antikörper oder mit einem Anti-Human-Schwerkettenspezifischen Antikörper (z. B. gegen Anti-Human-IgM zur Bestimmung des spezifischen IgM-Antikörpers) inkubiert.

- Bei der Verwendung von Fängerantikörper-beschichteten Reaktionsgefäßen sind nach der Seruminkubation die zu bestimmenden Antikörper neben anderen Antikörpern gebunden. Spezifität wird durch die folgende Inkubation mit einem zum zu bestimmenden Antikörper korrespondierenden Antigen hergestellt. Abschließend erfolgt eine Inkubation mit einem enzymmarkierten Antikörper gegen das gebundene Antigen. Die Reaktion kann vereinfacht werden, wenn das Antigen selbst enzymmarkiert wird (sog. ,enzyme-labelled antigen assay“).

Den einzelnen Assayschritten sind Waschschritte ( $\triangleright$ Washer) zur Entfernung unspezifischer und ungebundener Probenbestandteile zwischengelagert. Das gekoppelte Enzym kann z. B. eine Phosphatase oder Peroxidase sein, die in der Lage sind, durch Substratumsatz eine Änderung der Farbe oder der Farbintensität des Reaktionsansatzes herbeizuführen. Diese ist direkt proportional zur Menge des zu bestimmenden Antigens.

\section{Literatur}

Marja E. Koivunen, Richard L. Krogsrud, (2006) Principles of Immunochemical Techniques Used in Clinical Laboratories. Laboratory Medicine 37(8):490-497 